\title{
(Ineffective) Messages to Encourage Recycling: Evidence from a Randomized Evaluation in Peru
}

\author{
Alberto Chong, Dean Karlan, Jeremy Shapiro, and Jonathan Zinman*
}

There is growing interest in using messaging to drive prosocial behaviors, which contribute to investment in public goods. We worked with a leading nongovernmental organization in Peru to randomize nine different prorecycling messages that were crafted on the basis of best practices, prior evidence, and theories of behavioral change. Different variants emphasized information on environmental or social benefits, social comparisons, social sanctions, authority, and reminders. None of the messages had significant effects on recycling behavior. However, reducing the cost of ongoing participation by providing a recycling bin significantly increased recycling among enrolled households. JEL codes: D03, Q53, N56, C93

Evidence from psychology and behavioral economics has spurred interest in using low-cost messaging rather than lowering economic barriers to drive prosocial and other investment behaviors. There is mounting evidence that in certain contexts, simple, timely bits of information, reminders, cues/primes, or even pure framing can drive behavior. ${ }^{1}$ One area of focus has been the environment, specifically whether messaging can help solve collective action problems by increasing conservation behaviors.

*Alberto Chong (corresponding author) is a professor at the School of International Development and Global Studies and Department of Economics, University of Ottawa, and an affiliated professor in the Department of Economics, Universidad del Pacífico; his email is achong@uottawa.ca. Dean Karlan is a professor in the Department of Economics, Yale University, and the president and founder of Innovations for Poverty Action; his email is dean.karlan@yale.edu. Jeremy Shapiro’s email is jeremypshapiro@gmail. com. Jonathan Zinman is a professor in the Department of Economics, Dartmouth College, and a research affiliate at Innovations for Poverty Action; his email is jzinman@dartmouth.edu. We would like to thank three anonymous referees and the editors, Elisabeth Sadoulet and Alain de Janvry, for comments and suggestions. Thanks to Laura Litvine, Kartik Akileswaran, Elana Safran, Rachel Strohm, Beniamino Savonitto, Donghyuk Kim, and Glynis Startz for their outstanding research assistance and project management. Thanks to Diana Gil Ramirez, Juan Manuel Hernández-Agramonte, Miguel Paredes, and the team of Innovations for Poverty Action for the excellent support during field work. Finally, a special thanks to PRISMA for their collaboration in the study. The standard disclaimer applies. A supplemental appendix to this article is available at http://wber.oxfordjournals.org.

1. See, e.g., Nudge by Thaler and Sunstein (2008); Bertrand et al. (2009) on advertising; Choi et al. (2012) on savings cues; Karlan et al. (2011) on reminders; Stango and Zinman (2011) on overdrafts; and Zwane et al. (2010) on survey measurement.

THE WORLD BANK ECONOMIC REVIEW, VOL. 29, NO. 1, pp. 180-206

doi:10.1093/wber/lht022

Advance Access Publication August 1, 2013

(C) The Author 2013. Published by Oxford University Press on behalf of the International Bank for Reconstruction and Development / THE WORLD BANK. All rights reserved. For permissions, please e-mail: journals.permissions@oup.com 
We focus on whether and how messaging can increase recycling. Our work builds on several prior field experiments on recycling behavior, most of which were conducted in the United States or another developed country, and applies lessons from their results to a developing country context. ${ }^{2}$ Prior work has used a variety of types of messages; some have stressed information on the environmental benefits of recycling, whereas others have used descriptive information about the social norms surrounding recycling. A multifaceted message delivered in person by Boy Scouts increased recycling in a field experiment in Claremont, California, when solely informative messages were provided and when public commitment was added (Burn and Oskamp 1986). In a separate field experiment in LaVerne, California, door hangers providing feedback on individual or neighborhood recycling norms increased recycling, whereas informative hangers on how to sort trash and the environmental benefits of recycling did not (Schultz 1999). ${ }^{3}$ There is also evidence that when people are asked to recycle, the source of information (for example, whether the information comes from a neighbor or an anonymous written communication) matters (Burn 1991; Lord 1994). Prior research has shown that providing peer comparisons, such as the frequency with which one's peers engage in a behavior or the percentage of one's peers that approve of a behavior, is an effective catalyst for behavioral change (Cialdini and Goldstein 2004; Elster 1989).

Although there is evidence that messaging using social norms can be effective, there is also evidence that these effects depend on the specific context of the experiment and the presentation of the message. According to some researchers, these effects have been overemphasized in recent years. Schultz (1999) studied energy conservation among California residents and found that although normative social influence was rated very low by survey respondents as a motivation for conservation, experimental findings suggested that it actually had a greater effect on actions than many other influences. In contrast, Carlson (2001) found that in cases such as recycling, which is a large-number, small-payoff problem of collective action, researchers have overestimated the effects of social norm messaging in changing behaviors and suggested that governments should focus on financial incentives or reducing efforts to change behaviors.

In addition, these studies leave important questions about the characteristics of treated groups unanswered. Carlson suggests that the significant effects observed in social norm-oriented messaging might be positively related to, and dependent on, the long-term prorecycling views prevalent in the American population and that in a setting that lacks these views, treatment effects might be different. In Peru, although concerns about general environmental issues are as strong as in the United States, average views of recycling are far less reliably positive, and recycling itself is less well understood. Until recently, the separation of

2. For broader reviews of evidence on the drivers of recycling behavior, see, e.g., Carlson (2001) and Chu and Chiu (2006).

3. The Burn and Oskamp message included information on sorting, information on benefits to the environment, the local average participation rate, and an endorsement from the municipality. 
reusable refuse from garbage was performed by approximately 100,000 unofficial workers who reported that they were viewed and referred to as "scavengers" (Chauvin 2009). These baseline differences in the experimental population may cause different treatment effects than those found in a population in the United States or another developed country. Very little academic work has examined recycling in developing countries even though these are the places where insufficient waste management leads to huge environmental issues. This is one of the first studies to focus on interventions to increase recycling behaviors among the populations of these areas.

We have attempted to address these gaps by working with a leading Peruvian nongovernmental organization, PRISMA, to randomize nine different recycling enrollment messages that were crafted on the basis of best practices, prior evidence, and theories of behavioral change. The control group received PRISMA's standard marketing: door-to-door canvassing. The treatment groups, randomized at the household level, received the standard marketing in addition to a flier introducing the recycling program and a treatment message (described below). The treatment groups also received text messages.

On the basis of prior research, each enrollment treatment message was designed either to highlight a piece of general information on the benefits of recycling or to introduce a social comparison/influence. Following several prior studies, some messages provided general information by highlighting the benefits of recycling for the environment or the recycling workers. ${ }^{4}$ Following Cialdini and Goldstein (2004) and the oPower experiments (Alcott 2009), some messages emphasized conformity by highlighting a high rate of participation in nearby areas. Following Cialdini and Goldstein (2004), some messages provided social pressure by highlighting the fact that the participation rate for one neighborhood would be revealed to people in another neighborhood. ${ }^{5}$ Following Burn and Oskamp (1986) and Cialdini and Goldstein (2004), some messages emphasized authority by providing an explicit or implicit endorsement from the municipal government or the Catholic Church.

The relative effectiveness of these nine treatments was compared with a separate evaluation of three randomly assigned treatments meant to ease economic barriers to increased participation intensity in a sample of participants in the recycling program. One treatment provided a free recycling bin, ${ }^{6}$ and a second treatment provided a bin with a sticker displaying instructions on how to sort recyclables from nonrecyclables (that is, information on the logistics of recycling). These treatment groups were compared with a control group that received nothing. A separate treatment, randomized within the same group, sent weekly

4. See Gerber, Green, and Larimer (2008) on voting.

5. See Lerner and Tetlock (1999) on accountability; Gerber, Green, and Larimer (2008) on voter turnout; Frey and Meier (2004); and Alpizar, Carlsson, and Johansson-Stenman (2008) on social signaling in charitable giving.

6. See Bryce, Day, and Olney (1997) for results on paid versus free bins. 
short message service (SMS) reminders the day before recyclables would be picked up from the curb.

None of the enrollment messages had significant effects on recycling behavior. This null result is precisely estimated; we can rule out effects larger than 5 percentage points (or approximately 10 percent of the mean level of participation). Similarly, SMS reminders had no impact on recycling behavior. In contrast, providing a bin significantly increased the frequency and amount of recycling. Overall, the results suggest that reducing the time and effort of ongoing usage is more effective than messaging.

\section{Setting and Experimental Design}

Global polling data show that a majority of Latin Americans express concern about the environment, on par with other parts of the world. In the most recent round of the World Values Survey, 65 percent of Latin Americans agreed that they would "give part of [their] income if [they] were certain that the money would be used to prevent environmental pollution." In contrast, 52 percent of respondents in the United States, 37 percent of respondents in Germany, and 74 percent of respondents in Canada agreed with that statement (World Values Survey Association 2009). In another poll by the Pew Research Center, 73 percent of Latin Americans stated they would prioritize protecting the environment, even at the cost of slower economic growth or fewer jobs, compared with 66 percent of U.S. citizens, 77 percent of Canadians, and 75 percent of Germans (Pew Global Attitudes Project 2007).

Over 20,000 tons of solid waste is produced every day in Peru, much of which is dumped in waterways or left in informal dumps, making solid waste management an area of increasing concern in the country (Chauvin 2009). Various programs have been implemented across Peru to address the environmental issues posed by solid waste disposal. In 2002, PRISMA started a program called the "Improvement and Expansion of the Scope of Micro and Small Enterprise Solid Waste Management in the Districts of Piura, Castilla and Catacaos." This program provides technical assistance and training to help informal recyclers develop and launch small formal recycling businesses that engage in door-to-door recycling collection. The project has facilitated the creation of three recycling microenterprises and continues to expand with the dual goals of creating formal jobs for the informal trash collectors and increasing recycling.

To enroll new families in the recycling program, PRISMA conducts five-week-long marketing campaigns in areas where the three microenterprises do not currently work. In the first week, marketers visit households in the new area, present the program to them, and invite them to join. From the second to the fourth week, PRISMA's marketers accompany the recycler on his route 
across the new area to introduce him to the participating families. On the last visit, households that have given recyclables at least one time are given a sticker that is fixed near their door indicating that they participate in the program. During this period, households are provided with disposable recycling bags free of charge.

Once the initial marketing process ends, the recyclers are responsible for keeping families active in the program. Administrative data from PRISMA pertaining to the period before this study suggest that approximately 50 percent of households contacted by PRISMA's marketers join the program. However, because of the inability to contact all families, the program enrolls only approximately 34 percent of households residing in the intervention areas.

Working with PRISMA, we designed a two-part study to help expand the recycling program. The first part of the experiment tested different messaging treatments designed to increase enrollment in the door-to-door recycling program (the participation study), and the second tested different methods of increasing recycling compliance for those who participated in the program (the participation intensity study).

For the participation study, the experiment was built into PRISMA's expansion into new neighborhoods. ${ }^{7}$ In areas that had not previously received the program, we randomly provided 6,718 households with messages encouraging individuals to recycle their waste. We tested four main information campaigns: i) a focus on social norms, encouraging recipients to conform to the proenvironmental behavior of their peers; ii) a focus on social sanctions, informing individuals of others within and outside their community with whom the participation rates for their street would be shared; iii) an injunctive to recycle that was endorsed by religious or government authorities; and iv) a purely informational campaign with messages that stressed the social or environmental benefits of recycling and urged individuals to participate.

For the participation intensity study, we worked with a different sample of individuals than for the participation study. The participation intensity study used a sample frame of those already enrolled in the recycling program, meaning they had recycled through PRISMA previously. These individuals were randomly assigned to receive either a recycling bin with a sticker with information on recyclables, a recycling bin without a sticker, or no bin (control). The bin component is designed to lower economic barriers, as the bins reduce the cost of recycling by not requiring the purchase of recycling bags and by requiring less labor. Stickers test whether salient information on recycling increases the frequency and quality of participation.

As a subcomponent to the participation intensity study, individuals who provided their cell phone numbers to PRISMA were randomly assigned to receive a personalized weekly text message reminder, a generic weekly text message

7. As a result of its past experience, PRISMA does not enter the wealthiest zones, where families are reluctant to talk to the canvassers, or the poorest zones, which may be dangerous for the canvassers. 
reminder, or no reminder (control). The text message reminder component aimed to test whether limited attention is an important factor in participation in a recycling program.

Although the use of cell phones has grown recently in Peru, phones remain relatively expensive and are not affordable to all households. The full impact of the campaign was only experienced by households that both owned a cell phone and were willing to share their phone number because only these households received the reinforcement text messages prior to the marketing agent visit. As shown in supplemental table S1.1, cell phone owners in the participation study were slightly richer, more educated, and more interested in local affairs (especially recycling matters) than non-cell phone owners. This factor is important to note when considering the external validity of the impact of the SMS message treatments.

\section{PARTICIPATION STUDY}

\section{Experimental Design ${ }^{8}$}

Prior to the marketing campaign, we conducted a baseline survey of all households in the area where PRISMA was planning to expand. A total of 6,718 families were included in the participation study in three rounds of expansion: the first with 1,804 households in the district of Castilla (March 2010) and the last two rounds in the district of Piura with 2,173 and 2,744 households, respectively (June 2010 and August 2010). Eighty-one percent of the households, or 5,436 families, were present at the time of surveying. Households were given one of two surveys: a short survey of questions to provide basic information for analysis (such as phone numbers, questions related to their economic situation, and opinions and interest in receiving information about recycling) or a long survey intended to provide detailed information from a representative sample of households in the area. Of the full sample, 523 families received a long survey. Supplemental table S1.2 provides summary demographic statistics and verifies that assignment to treatment was uncorrelated with the demographic information collected at the baseline.

After being surveyed, all households were randomly assigned to treatment groups for messages, detailed below, aimed at increasing participation. One week before PRISMA began marketing, a flier with the assigned message was delivered to the household. We received valid phone numbers for approximately 35 percent of the sample and sent those people SMS messages that reiterated the flier's message on the night before the marketer's visit and once a week through the end of the study. If people were present when the flier was delivered, a short verbal summary of the message accompanied the flier; if no one was home, the

8. Supplemental tables S1.6a and S1.6b show the treatments and hypotheses for each section of the study. 
flier was left on the doorstep. Sixty-five percent of fliers were delivered in person, 32 percent were left on the doorstep, and three percent failed to be delivered. An orthogonality check on these two groups did not raise any important concerns (see supplemental table S1.1b). ${ }^{9}$ The implementation of the text message campaigns was less successful. Because of technical limitations, only 80 percent of the SMS messages that were sent reached their destination. The technical difficulties were especially problematic in the first wave of the study, when approximately 60 percent of the messages were received by the households. ${ }^{10}$

We randomly assigned the households found in the baseline to 10 groups (nine treatment and one control), stratifying by street and household presence during the prestudy survey. The treatment groups conformity wealthy, conformity poor, signaling wealthy, signaling poor, authority religious, authority municipal, environmental emphasis, and social emphasis accounted for 8.75 percent of the sample each, whereas the signaling proximate treatment was assigned to 12.5 percent of the sample. We explain each treatment below. Because we will conduct the analysis by combining related treatments (conformity wealthy with conformity poor, signaling wealthy with signaling poor, and environmental emphasis with social emphasis), we randomized such that the signaling proximate treatment would be overrepresented to maximize power. The remaining 17.5 percent of the sample was assigned to the control group, which did not receive a flier or a text message and was canvassed according to PRISMA's usual procedure. The division of the sample into treatment groups is presented in table 1, panel A.

All fliers included both a generic message about PRISMA's program- "Do you know that an association of recyclers is starting a recycling program in your area? By recycling, you help both the environment and the informal collectors to get a formal and decent job"-and a treatment message (except for the control group). The text message only contained the treatment message. The treatment messages printed on the fliers and contained in the SMS message were formulated to allow us to provide evidence for the following questions:

\footnotetext{
Do social norms and peer comparisons affect recycling program enrollment?

If yes, do peer effects operate through conformity, defined as seeking to emulate the behavior of peers (Cialdini and Goldstein, 2004), or signaling, defined as seeking peers' approval? (Gerber, Green, and Larimer, 2008)

Is proenvironmental behavior influenced by authority? (Cialdini and Goldstein, 2004)

Is recycling behavior influenced by emphasizing the benefits of recycling? Are there differential effects for mentioning environmental or social (employment) benefits?
}

9. The only difference significant at more than a 10 percent level was the number of persons in the household. Those households in which the flyer had to be left at the doorstep were slightly smaller on average. Because a larger household is presumably more likely to have someone present at any point in time, this issue does not seem overly concerning. Significant at the 10 percent level, households with flyers delivered in person were slightly more likely to use "advanced fuel" for cooking but slightly less likely to have a color TV.

10. The service provider that sent the SMS messages provided reports of whether the message reached the intended phone, from which we estimated the delivery success rate. Network failures, off phones, and incorrect phone numbers were the main factors for delivery failure. 
Ta ble 1: Both Participation and Participation Intensity Studies - Treatment Assignment

\begin{tabular}{|c|c|c|c|c|c|}
\hline PANEL A: Participation study & Without cell phone & With cell phone & Total & & \\
\hline Any message & 3,129 & 2,432 & 5,561 & & \\
\hline Norms, rich & 352 & 242 & 594 & & \\
\hline Norms poor & 327 & 253 & 580 & & \\
\hline Signal, rich & 328 & 252 & 580 & & \\
\hline Signal, poor & 328 & 252 & 580 & & \\
\hline Signal, local & 533 & 399 & 932 & & \\
\hline Religious & 310 & 265 & 575 & & \\
\hline Municipality & 310 & 250 & 560 & & \\
\hline Environmental emphasis & 318 & 263 & 581 & & \\
\hline Social emphasis & 323 & 256 & 579 & & \\
\hline No Message & 643 & 514 & 1,157 & & \\
\hline Totals & 3,772 & 2,946 & 6,718 & & \\
\hline \multicolumn{6}{|l|}{ TOTAL $=6,718$} \\
\hline \multicolumn{6}{|c|}{ PANEL B: Participation intensity study } \\
\hline & \multirow[t]{2}{*}{ Without cell phone } & \multirow[t]{2}{*}{ With cell phone } & \multicolumn{3}{|c|}{ With cell phone subtreatments } \\
\hline & & & Generic SMS message & Personal SMS message & No SMS message \\
\hline Bins with sticker & 167 & 132 & 42 & 45 & 45 \\
\hline Bins without sticker & 160 & 140 & 45 & 50 & 45 \\
\hline No bin & 629 & 557 & 186 & 183 & 188 \\
\hline Totals & 956 & 829 & 273 & 278 & 278 \\
\hline TOTAL $=1,785$ & & & & & \\
\hline
\end{tabular}

Note: Tables show distributions of treatment assignment for both participation and participation intensity studies. 
CONFORMITY (CONFORMITY WEALTHY AND CONFORMITY POOR GROUPS). Messages encouraging individuals to behave as well as others by describing the majority's behavior as an existing norm have been shown to influence the adoption of environmentally friendly behaviors (Cialdini and Goldstein 2004). Goldstein, Cialdini, and Griskevicius (2008) show that the power of descriptive norms varies according to the reference group to which the participant is compared. We designed two "conformity messages" that described high participation rates for the program in other neighborhoods. ${ }^{11}$ We varied whether the reference neighborhood was of high or low socioeconomic status, which may have affected the degree to which people identified with the reference group and responded to the message. The exact wording on the flier and in the SMS message was as follows: "In parts of [nearby wealthy/poor area], more than 75 percent of the families participate in the recycling program. Join them!"

SigNALING (SIGNALING WEALTHY, SIGNALING POOR, AND SIGNALING PROXIMATE GROUPS). A large body of literature in social psychology shows that individual behaviors are influenced by how public people perceive their actions to be (Cialdini and Goldstein 2004; Lerner and Tetlock 1999). Gerber, Green, and Larimer (2008) show that inducing social pressure by telling individuals which of their peers will be informed of their actions can increase voting, which is a prosocial behavior like recycling. These authors also demonstrate that different levels of proximity to those peers may have a stronger or weaker influence on one's actions, either by signaling a desirable trait about an individual to those who observe the individual (for example, voting indicates one is civic minded, whereas recycling indicates a person is a responsible steward of the earth) or by motivating individuals to take certain actions through punishment or the threat of punishment, whether by criticism or social sanction.

We sought to understand whether this effect would persist when the information pertained to a group with which an individual identified rather than a specific individual. Although there may be other factors involved, we chose to reveal the actions of groups of people (those living on the same street) to other groups, which had plausibly different abilities to sanction members of the group whose actions were public. We informed households on certain streets that the participation level of their street would be revealed to others on nearby streets with whom they were likely to have direct interaction and from whom they might face direct criticism for choosing not to participate. We informed other households that the information would be revealed to individuals in more distant areas. Individual survey responses indicate that the reputation of the household within its local community was important, as was the reputation of the community in the larger urban area. Thus, the motivation to signal should be present when information is revealed locally and to more distant communities, but the threat of

11. These participation rates are accurate although they are based on back-of-the-envelope calculations. 
potential social sanction is more likely to be present when information about participation is revealed locally.

One message encouraged individuals to set an example for their geographically proximate peers: "In order for more families on the other side of the street to participate in the recycling program, we will inform them of how many participated on your side of the street. Set a good example for them!" We refer to this message as "signaling proximate." For distant areas, we again chose areas with high or low socioeconomic status. The specific wording of the messages referencing distant communities was as follows: "In order for more families in [a wealthy /poor area] to participate in the recycling program, we will inform them of how many participated in your area. Set a good example for them!" We refer to these messages as "signaling wealthy" and "signaling poor."

AUTHORITY (AUTHORITY RELIGIOUS AND AUTHORITY MUNICIPAL GROUPS). One of the most memorable and important contributions to the study of how social forces influence behavior is Milgram's (1974) famous work on the role of authority in compliance. Milgram's work and the work that followed showed that individuals have a strong tendency to conform to norms that are presented to them by authority figures (Cialdini and Goldstein 2004). To test whether authority is relevant in promoting environmentally friendly behaviors, we designed two messages that presented participation in the recycling program as being in accordance with the wishes of a higher authority. Because a large proportion of the population is religious, one message cast participation in the recycling program as consistent with religious ethics. The message, which we refer to as "authority religious," read, "Protect the Earth that God created for all. Participate in the recycling program! Recycle!" The message was limited to a mention of religious principles rather than authorities because the local religious authorities preferred not to be mentioned in the campaign. The other treatment, "authority municipal," invoked local government authority in advocating participation in the recycling program. This message read, "The Municipality of [Piura/Castilla] invites you to participate in the recycling program. Recycle!", encouraging families to participate in their named municipality.

BENEFITS OF RECYCLING (ENVIRONMENTAL EMPHASIS AND SOCIAL EMPHASIS GROUPS). In a review of the literature on possible interventions to solve large-number, smallpayoff issues, Carlson (2001) noted that informational campaigns that emphasize the benefits (for example, social or environmental) of the "good" way to behave are very commonly used. In studying the effect of social pressure on voter turnout, Gerber, Green, and Larimer (2008) showed that generic messages appealing to what people know to be right had a positive influence on individual behaviors, but this influence was not as large as the effect they observed for messages that induced direct social pressure to behave a certain way. Although many informational campaigns advocating proenvironmental behaviors emphasize the environmental benefits of certain actions, in this particular context, choosing to 
participate in the recycling program had both environmental and local social benefits in the form of the formal job created for the collectors.

To understand whether making the local social benefits of participation salient to individuals would have a differential impact than the more traditional route of emphasizing the environmental benefits of participation, we added two messages appealing to people's conscience. One emphasized environmental benefits, and the other emphasized local social benefits for the recyclers. The message in the environmental emphasis treatment read, "By recycling, you will take care of the environment and make our city cleaner. Participate in the recycling program! Recycle!" The social emphasis message read, "By recycling, you will help the informal collectors get a formal and more decent job. Participate in the recycling program! Recycle!"

\section{Outcome Collection and Measurement}

The outcome measures come from administrative data from PRISMA. These data specify whether the family took up the program when solicited by PRISMA marketers and whether the household turned in recyclables in each of the following four weeks. ${ }^{12}$

On the basis of these data, we consider three outcome variables to represent a household's participation in the recycling program:

\footnotetext{
"Participates at any time" is an indicator equal to one if the family participated in the program and gave at least once.

"Participation ratio" is the ratio of the number of times a household turned in residuals over its number of opportunities to turn in residuals. This variable measures the strength of commitment to the program. In constructing this measure, the denominator, opportunities to turn in residuals, includes instances in which there was no one at the household when the residual collector visited.

"Participates during either of last two visits" is an indicator of whether the household turned in residuals during one of the last two canvassing weeks (weeks $n$ and $N$ of the marketing/enrollment campaign). It measures the initial persistence of households' commitment to the program.
}

During the data collection process, we were unable to obtain outcome data for 1,468 houses owing to coordination problems with PRISMA, household migration, and households choosing to combine their recyclables with other households, which were excluded because we had no way of determining what percentage of recycling came from each participant. We were therefore unable to construct accurate outcome values for these households. We tested for differential attrition rates between treatment groups and found no significant differences. Our final sample for the participation study comprised 5,250 households. ${ }^{13}$

12. PRISMA considers a household to be "participating" if it gave residuals to the collector at least once during the trial period.

13. Attrition in the treatment and control groups was 0.130 and 0.138 , respectively. With a p-value of 0.449 , a t-test failed to reject the null hypothesis that these are equal. 


\section{Results: Effect of Treatments on Participation}

Using an intent-to-treat framework, we find no significant treatment effect from receiving any of the marketing messages on participation or participation intensity compared with the control (no message) group. The personal visit from the canvassing agent was made no more (or less) effective by the precanvassing distribution of marketing material. We show this in a regression framework (table 2, panel A and table 3). Because the marketing message was reinforced by cell phone (in addition to the flier), we also analyze the data for the subsample that provided a cell phone number. We similarly find no effect from the marketing message on the subsample for which the treatment also included an SMS message (regression results available in supplemental table S1.3).

For the regression framework, we use the following specification:

$Y_{i}=\beta T_{i}+\alpha_{j}+\varepsilon_{i}$

where $Y$ indicates our outcome of interest (participates at any time, take-up ratio, and participates during last visits), $T$ takes the value of one if the household

TA в LE 2: Both Participation and Participation Intensity Studies - Overall Treatment Effect from Receiving Any Treatment

\begin{tabular}{lccc}
\hline & $\begin{array}{c}(1) \\
\text { Participates at } \\
\text { anytime }\end{array}$ & $\begin{array}{c}(2) \\
\text { Participation } \\
\text { ratio }\end{array}$ & $\begin{array}{c}(3) \\
\text { Participates during either } \\
\text { of the last 2 visits }\end{array}$ \\
\hline $\begin{array}{l}\text { PANEL A: Participation study } \\
\text { Treatment }\end{array}$ & 0.002 & 0.008 & 0.001 \\
Observations & $(0.016)$ & $(0.037)$ & $(0.016)$ \\
R-squared & 6717 & 6717 & 6717 \\
Mean of dependent variable & 0.055 & & 0.065 \\
Sd of dependent variable & 0.506 & 0.332 & 0.402 \\
& 0.500 & 0.392 & 0.490 \\
PANEL B: Participation intensity study & & & \\
Treatment & 0.005 & $0.129^{* *}$ & 0.021 \\
& $(0.007)$ & $(0.053)$ & $(0.020)$ \\
Observations & 1782 & 1782 & 1782 \\
R-squared & 0.121 & & 0.117 \\
Mean of dependent variable & 0.978 & 0.691 & 0.793 \\
Sd of dependent variable & 0.146 & 0.223 & 0.405 \\
\hline
\end{tabular}

Notes: The table shows the results of measures of household's participation in the program (whether they ever turned in recyclables, the percentage of times they turned in recyclables or whether they turned in recyclables in one of the last two times they were visited) regressed on a treatment indicator that the household was randomly assigned to in each study. OLS models are used for Columns 1 and 3 and Ordered Probit Model is used for Column 2. One observation from Table 1 is excluded in Panel A because of a missing value for the street variable. Robust standard errors are shown in parentheses. All regressions include street fixed effects. Stars denote significance level of the difference: * Significant at the $10 \%$ confidence level, * Significant at the $5 \%$ confidence level, $* * *$ Significant at the $1 \%$ confidence level 
Table 3: Participation Study - Treatment Effect of Each Different Message on Households' Decisions to Participate.

\begin{tabular}{lccc}
\hline & $(1)$ & $(2)$ & $(3)$ \\
& $\begin{array}{c}\text { Participates at } \\
\text { anytime }\end{array}$ & $\begin{array}{c}\text { Participation } \\
\text { ratio }\end{array}$ & $\begin{array}{c}\text { Participates during either } \\
\text { of the last 2 visits }\end{array}$ \\
\hline Norms, Rich & -0.007 & -0.023 & -0.020 \\
Norms, Poor & $(0.025)$ & $(0.058)$ & $(0.024)$ \\
& 0.022 & 0.027 & 0.014 \\
Signal, Rich & $(0.025)$ & $(0.057)$ & $(0.024)$ \\
& 0.008 & 0.061 & 0.015 \\
Signal, Poor & $(0.025)$ & $(0.059)$ & $(0.025)$ \\
& -0.008 & -0.040 & -0.023 \\
Signal, Local & $(0.025)$ & $(0.059)$ & $(0.025)$ \\
& -0.018 & -0.007 & -0.006 \\
Religious & $(0.022)$ & $(0.051)$ & $0.021)$ \\
& 0.005 & 0.020 & 0.002 \\
Municipality & $(0.025)$ & $(0.059)$ & 0.002 \\
& 0.022 & 0.009 & $(0.025)$ \\
Environmental emphasis & $(0.026)$ & $(0.059)$ & 0.015 \\
& 0.004 & 0.032 & $(0.025)$ \\
Social Emphasis & $(0.025)$ & $(0.058)$ & 0.013 \\
& 0.003 & 0.004 & $(0.024)$ \\
Observations & $(0.025)$ & $(0.058)$ & 6717 \\
R-squared & 6717 & 6717 & 0.066 \\
Mean of dependent variable & 0.056 & & 0.402 \\
Sd of dependent variable & 0.506 & 0.332 & 0.490 \\
& 0.500 & 0.392 &
\end{tabular}

Notes: The table shows results of measures of households' participation in the program (whether they ever turned in recyclables, the percentage of times they turned in recyclables or whether they turned in recyclables in one of the last two times they were visited) regressed on all specifications of the treatment in the participation study. OLS models are used for Columns 1 and 3 and Ordered Probit Model is used for Column 2. Each specification corresponds to a particular framing of the extra information delivered. One observation from Table 1 is excluded in Panel A because of a missing value for the street variable. Robust standard errors are shown in parentheses. All regressions include street fixed effects. Stars denote significance level of the difference: * Significant at the $10 \%$ confidence level, $*$ Significant at the $5 \%$ confidence level, $* *$ Significant at the $1 \%$ confidence level.

received a flier or SMS message, and $i$ indexes households. In the subsequent analysis, we replace $T$ with a full set of dummies for each of the treatment messages. In all specifications, the control group is the omitted category. The regression equation includes street fixed effects $(\propto)$ because randomization was stratified by street.

We are able to rule out a modest treatment effect; that is, we estimate a null effect fairly precisely (table 2, panel A and table 3). For any treatment, an effect of anything greater than 5 percentage points lies outside the 95 percent confidence interval. We also analyze subsamples of respondents on the basis of whether they were handed the flyer in person or had it left on their doorstep, and we find similar results. 


\section{Discussion of Participation Study Results}

In this section, we discuss possible explanations for the null results. First, we address the possibility that these results are simply due to experiment design or implementation. Second, we address possible reasons for the ineffectiveness of messaging campaigns.

The first aspects of internal validity that must be explored are issues related to attrition, receipt and understanding of treatment, and spillover effects. Orthogonality checks performed on attritors suggest this is not a likely explanation for the results. Although we do not have information from the households that allows us to test precisely whether they received and understood the messages, neither of these factors is likely to have contributed to internal validity failures. Over half of the flyers were delivered in person, and we have similar data on the receipt of SMS messages. Understanding is also not likely to have been an important contributing factor; all treatments were quite simple, and everyone received the in-person visit and therefore was likely to have a basic understanding of recycling. We did not find any outstanding issues related to possible spillover effects that may have affected our findings. In this regard, the data were thoroughly checked, and we found no evidence of this issue when testing for possible heterogeneity between the treated and control areas even on the same streets.

This finding leads to an aspect of the experimental design that we believe may have been a contributing factor to the lack of effectiveness of messaging: PRISMA's in-person marketing campaign. The personal marketing visit may have swamped the treatment effects of the messaging such that without the personal marketing visits, the messaging would have changed behavior. In other words, people who do not respond to a personalized visit may be more committed nonrecyclers and may be unresponsive to messaging treatments, but those who do respond to a personalized visit may have responded to a messaging treatment even if they had received one without a personalized visit. This issue is not one of internal validity, but it does make the results less widely applicable. Because the messaging treatments were tested in an environment in which everyone received a personalized visit to promote recycling, we can only conclude that messaging is ineffective under those specific constraints. Burn and Oskamp (1986) also used a mix of in-person visits and written messaging, but their control group received neither. Their results showed a large, significant increase in recycling behavior for all treatments relative to their control but no significant differences between the three treatment arms. Although not conclusive, this finding provides further evidence that in-person visits may be the most important factor in incentivizing good recycling behavior.

We propose several other explanations for the failure of the treatment to generate an increase in participation or participation intensity. One possible explanation is that the messages may have been inappropriate for this context because they were motivated by studies in the United States, where there are different norms, attitudes, and knowledge about recycling. A related explanation is that 
the strength of opinions may differ. It is difficult to find information on attitudes specific to recycling, but we were able to look more closely at the environmental questions from the World Values Survey (2005) in Peru and the United States. As noted previously, Peruvians were just as likely as Americans to report that they felt that protecting the environment was important and were more likely to report willingness to give part of their income for the environment ( 77 percent compared with 51 percent). They were also more likely to be amenable to tax increases if the government provided environmental protection. Furthermore, the Peruvians interviewed were no less likely than Americans to "agree strongly" with these statements, a potential proxy for the level of commitment to environmental action, suggesting that strength of norms or additions is unlikely to provide a clear explanation for the null result. Other environmental questions in the survey asked respondents about their views on the importance of various local and global environmental problems. The respondents surveyed in the United States exhibited no more concern about these issues than those in Peru. Although these numbers can provide only a rough proxy for specific attitudes about recycling, they suggest that this is not an obvious rationale for the differing results between earlier American trials and our study. Potentially, however, because these numbers reflect more serious global and local environmental concerns, they may not accurately capture views on recycling. Peruvians who are faced with more serious problems close to home might feel that recycling is much less serious than other concerns and may be less willing to expend energy on it.

A possible related explanation is that the messages, which were modeled on those from several different studies in the United States, failed because the subjects of this experiment had norms to which they wanted to conform. For instance, they may have felt more or less desire to conform to the expectations of the church or a local authority. Once again, the World Values Survey allowed us to examine very rough proxies for several of the messages on the basis of church and authority (national instead of local), and there was no evidence that Peruvians felt less strongly than Americans. This argument also seems less valid than other possibilities because none of the messages had any significant effect and none differed significantly from the others. If there were differing norms, one might expect some messages to work while others failed.

A third explanation, based on our own surveys, involves the fact that individuals in Peru seem to believe that active recycling through a formal program is no better for the environment than the existing informal recyclers (who scavenge recyclable items from trash bags and dumps and may be even more effective at sorting). Thus, from an environmental perspective, the formal process requires more effort and does not change the ultimate outcome. This explanation has the benefit of explaining why similar messaging was successful in the United States, where such informal recycling exists but is far less prevalent, but was not successful in Peru. 


\section{PaRTICIPATION INTENSITY STUdY}

\section{Experimental Design}

In addition to the enrollment study, we conducted a participation intensity study among individuals who had previously enrolled in the recycling program, meaning that they had recycled through PRISMA at some point in the past. The purpose of this second phase was to assess whether failure to regularly remit recyclables might be attributable to either forgetfulness or the costs of participating, including time costs or the inconvenience of storing recyclables for a week. In the participation intensity study, we randomly assigned program households to receive a bin with an informative sticker about how to recycle, a bin without an informative sticker, or no bin. The bin experiment tests the hypothesis that the inconvenience or cost of recycling hinders participation because households report that bags are often too small and inconvenient for recycling. The sticker treatment tests the hypothesis that lack of knowledge contributes to the high contamination of recyclables, which is a considerable problem for collectors.

Independently of the bin randomization, we also randomly assigned households with a cell phone number to one of two SMS reminder treatment groups or a control group that received no message. Prior research has found that identity and social context can dramatically change the impact of a message (Cialdini and Goldstein 2004). As such, half of the SMS messages were generic reminders, and half were personalized messages stating the name of the recipient and the name of the collector asking their client to remember to recycle. These messages were sent weekly to each phone number on the evening before the collector was scheduled to pick up the recyclables. Approximately 80 percent of the messages reached the intended recipient. ${ }^{14}$

A total of 1,802 individuals who were already enrolled in the recycling program were identified in different zones of the district of Castilla. We visited the individuals at their homes to administer a short survey that captured basic demographic information and requested cell phone numbers and permission to contact respondents with information about recycling. A longer survey that captured more precise information about socioeconomic situations and recycling behavior was administered to 10 percent of the sample. All households were randomly assigned into treatment groups. During the data collection, 17 households could not be located, largely because the household moved elsewhere. We dropped these observations from our analysis, leaving a sample of 1,785 households in the participation intensity study. Of these households, approximately 50 percent (829 observations) provided a valid cell phone number. Among these, we randomly assigned households to one of three equal-sized groups: a generic SMS message group, a personalized SMS message group, and a control

14. The service provider that sent the SMS messages provided reports of whether the message reached the intended phone, from which we estimated the delivery success rate. Network failures, off phones, and incorrect phone numbers were the main factors in delivery failure. 
group that received no text message. This randomization was stratified at the street level.

The 1,785 households were then randomly assigned to receive a plastic bin to store their recyclables, a plastic bin with a sticker, or no bin (that is, single-use plastic bags, which are normally distributed). We stratified this randomization on the SMS message treatment assignment. In total, 299 households received a bin with informational stickers attached, 300 received an unadorned bin, and 1,186 received no bin. Table 1, panel B shows how the sample was divided into randomly assigned treatment groups.

\section{Outcome Collection and Measurement}

The data collection phase of the participation intensity study lasted eight weeks. The first two weeks were dedicated to the baseline measurement before the bins were distributed or SMS messages were sent, and the following six weeks were dedicated to outcome data collection. During the data collection, an observer accompanied each recyclable collector on his route to track the participation intensity of each household and to measure the quantity and quality of the recyclables remitted.

On the basis of the data collected during these visits, we consider the following outcome variables:

\footnotetext{
"Percentage of visits turned in bag" indicates the proportion of weeks in which the household had an opportunity to turn in a bag or bin of recyclables and in which they actually did so. In calculating this percentage, we treat an absence as not turning in recyclables.

"Average number of bins turned in per week" indicates the average volume of recyclables turned in to the collector, measured by the number of full standard-sized bins given to the collector over the six weeks of posttreatment data collection. ${ }^{15}$

"Average weight (in $\mathrm{kg}$ ) of recyclables turned in per week" indicates the average weight of recyclables given over the six weeks of posttreatment data collection.

"Average market value of recyclables turned in per week" indicates the average value of the recyclables that were given in terms of prices received by the collector for the items collected over the six weeks of posttreatment data collection.

"Average percentage of contamination per week" indicates the average percentage of nonrecyclables (by weight) mixed in with the recyclable items over the six weeks of posttreatment data collection.
}

\section{Results: Effect of Treatments on Participation Intensity}

Baseline summary statistics reveal that participation intensity with the PRISMA program was fairly high among the households that had previously indicated their willingness to participate; these households turned in a bag on 78 percent of the visits. On the intensive margin, in terms of the quantity of recyclables given (measured by volume in terms of the number of bins of a fixed size turned in and in terms of weight as measured by kilograms), however, there may be room to increase participation. Moreover, at baseline, more than 15 percent of

15. Scaling by the number of the people in the household yields no differences in results. 
the items turned in by weight were nonrecyclable items, or "contamination," which must be separated by the collectors.

As a first look at the effects of the interventions, we plot the mean of various measures of participation by treatment status. Looking first at the bin treatments, we find that bins have a positive impact on participation: the recipients of bins turned in recyclables with a higher frequency (that is, they turn in items on more weekly visits) and turned in higher quantities of recyclables, measured both in volume and weight, than households that did not receive a bin. Along these dimensions, we do not see a clear difference between the bins with stickers and those without. The recipients of bins also included fewer nonrecyclable items with their recyclables, a phenomenon that appears to be driven by households that received bins with stickers indicating which items were recyclable.

Turning to SMS message treatments, our findings do not indicate a clear impact of SMS reminders. In fact, for some outcomes, it appears that recipients of personal SMS messages turned in fewer recyclables than households that received no message. It should be noted, however, that this figure, as well as the preceding one, ignores interaction effects (because some households received both bins and SMS messages) and omits potentially important control variables, including whether the household had a cell phone, street characteristics, and baseline participation levels.

To address the issue of interaction effects, we plot outcomes for every possible combination of bin and SMS message treatments and find that individuals who received a bin, in combination with a SMS message or alone, tended to turn in recyclables more often and in larger quantities. It also appears that individuals who received a bin with an informational sticker reduced contamination more than other households, although this was less apparent among the group of households that did not have a cell phone. ${ }^{16}$

To assess the statistical significance of these differences and to control for stratification variables and the baseline value of the outcome variable, we turn to regression analysis.

In particular, we estimate the following:

$y_{i s}=\beta_{1} B_{g}+\beta_{2} B_{s}+P_{i s}+\lambda y_{b l i s}+\alpha_{j}+\varepsilon_{i}$

where $y$ indicates our outcome of interest, $i$ indexes the household, $B_{g}$ is an indicator that the household received a generic bin (without a sticker), and $B_{s}$ is an indicator that the household received a bin with an informational sticker (not receiving a bin is the omitted category). $P$ is an indicator variable capturing whether the household had a cell phone, which is included because it is correlated with SMS message assignment, and $Y_{b l}$ is a baseline measure of the outcome

16. Figures showing these findings are available upon request. In addition, we performed a simple two-stage Heckman selection equation and found no difference between the groups. 
for that household. The regression equation also includes street fixed effects $(\propto)$ because the randomization was stratified by street.

We estimate this equation separately among households that did not have a cell phone and those that had a cell phone but did not receive a SMS message, in which case $P$ drops out of the equation and interaction effects are not a concern. We also estimate the equation on the full sample.

Table 4 presents the results, demonstrating that the receipt of the bin had positive effects on participation behaviors. We find that households that received a bin were 4.5 percentage points more likely to turn in recyclables (panel A), which represents a 6 percent increase over the sample mean for this outcome. The point estimates suggest that the magnitude of the effect is stronger for bins with stickers (panels B and C), but for the most part, we fail to reject the equality of the coefficients for receiving the bin with and without the sticker.

With respect to other measures of participation intensity, the volume, weight, and market value of recyclables given, we detect larger effects (measured as a percentage of the sample mean of the outcome) that are highly statistically significant both among households without a phone and the full sample. In terms of the effect on contamination, the point estimates indicate that receiving a bin reduces the degree of contamination, but these estimates are generally not significantly different from zero.

We also estimate equation (2), in which we replace $B_{g}$ and $B_{s}$ with $S_{g}$ and $S_{p}$, indicator variables that the household received an impersonal or personal text message, respectively. We restrict this analysis to the sample with a cell phone, the sample with a cell phone that did not receive a bin (where interaction terms are irrelevant), and the whole sample. The results of the latter specification are presented in table 5 , and the split sample is presented in panels A and B, respectively, of supplemental table $\mathrm{S} 1.5$. The results fail to indicate any statistically significant effect of SMS reminders to recycle, which is consistent with the graphical presentations discussed above.

Finally, we examine these effects simultaneously and account for interaction effects. We estimate each of the following equations:

$$
\begin{aligned}
& Y_{i}=\beta_{1} B+\beta_{2} S+\lambda Y b l_{i}+P_{i}+\alpha_{j}+\varepsilon_{1} \\
& Y_{i}=\beta_{1} B_{g}+\beta_{2} B_{s}+\beta_{3} S_{g}+\beta_{4} S_{p}+\lambda Y b l_{i}+P_{i}+\alpha_{j}+\varepsilon_{1} \\
& Y_{i}=\sum_{j} \beta_{j} T_{j}+\lambda Y b l_{i}+P_{i}+\alpha_{j}+\varepsilon_{i}
\end{aligned}
$$

where $B$ and $S$ are indicator variables that the household receives any bin or any SMS message treatment. In equation $(5) T_{j}$ denotes a distinct combination of bin and SMS message treatment; the omitted category is having no phone and receiving no bin. 
TA B LE 4: Participation Intensity Study - Treatment Effect of Bins and SMS Messages on Recycling

\begin{tabular}{|c|c|c|c|c|c|}
\hline & $\begin{array}{l}\text { (1) } \\
\text { Percentage of visits } \\
\text { turned in bag }\end{array}$ & $\begin{array}{l}\text { (2) } \\
\text { Avg. no. of bins } \\
\text { turned in per week }\end{array}$ & $\begin{array}{l}\text { (3) } \\
\text { Avg. weight (in kg) of } \\
\text { recyclables turned in per week }\end{array}$ & $\begin{array}{l}\text { (4) } \\
\text { Avg. market value of } \\
\text { recyclables given per week }\end{array}$ & $\begin{array}{l}\text { Avg. percentage of } \\
\text { contamination } \\
\text { per week }\end{array}$ \\
\hline \multicolumn{6}{|c|}{ PANEL A: Main effects without interactions } \\
\hline Any bin (1) & $\begin{array}{l}0.045 * * * \\
(0.012)\end{array}$ & $\begin{array}{l}0.115^{* * *} \\
(0.017)\end{array}$ & $\begin{array}{l}0.187^{* * *} \\
(0.032)\end{array}$ & $\begin{array}{l}0.108 * * * \\
(0.018)\end{array}$ & $\begin{array}{l}-0.009 \\
(0.007)\end{array}$ \\
\hline Any SMS message (2) & $\begin{array}{l}0.002 \\
(0.014)\end{array}$ & $\begin{array}{l}0.005 \\
(0.021)\end{array}$ & $\begin{array}{l}-0.024 \\
(0.039)\end{array}$ & $\begin{array}{l}-0.02 \\
(0.022)\end{array}$ & $\begin{array}{l}-0.004 \\
(0.009)\end{array}$ \\
\hline Has cell phone & $\begin{array}{l}0.022 \\
(0.014)\end{array}$ & $\begin{array}{l}0.047^{* *} \\
(0.02)\end{array}$ & $\begin{array}{l}0.105 * * * \\
(0.038)\end{array}$ & $\begin{array}{l}0.057 * * \\
(0.022)\end{array}$ & $\begin{array}{l}0.01 \\
(0.008)\end{array}$ \\
\hline $\begin{array}{l}\text { Percentage of visits turned in bag, } \\
\text { baseline }\end{array}$ & $\begin{array}{l}0.374 * * * \\
(0.017)\end{array}$ & & & & \\
\hline $\begin{array}{l}\text { Avg. no. of bins turned in per week, } \\
\text { baseline }\end{array}$ & & $\begin{array}{l}0.373 * * * \\
(0.014)\end{array}$ & & & \\
\hline $\begin{array}{l}\text { Avg. weight (in } \mathrm{kg} \text { ) of recyclables } \\
\text { turned in per week, baseline }\end{array}$ & & & $\begin{array}{l}0.281^{* * * *} \\
(0.011)\end{array}$ & & \\
\hline $\begin{array}{l}\text { Avg. market value of recyclables given } \\
\text { per week, baseline }\end{array}$ & & & & $\begin{array}{l}0.232 * * * \\
(0.010)\end{array}$ & \\
\hline $\begin{array}{l}\text { Avg. percentage of contamination per } \\
\text { week, baseline }\end{array}$ & & & & & $\begin{array}{l}0.292 * * * \\
(0.019)\end{array}$ \\
\hline Street fixed effects & Yes & Yes & Yes & Yes & Yes \\
\hline F-test p-value: $(1)=(2)$ & 0.02 & 0 & 0 & 0 & 0.64 \\
\hline Observations & 1,781 & 1,781 & 1,781 & 1,781 & 1,588 \\
\hline R-squared & 0.34 & 0.44 & 0.38 & 0.35 & 0.34 \\
\hline Mean of dependent variable & 0.78 & 0.68 & 0.76 & 0.49 & 0.13 \\
\hline
\end{tabular}

Notes: The table shows household-level recycling variables in the participation intensity study regressed on indicators for any SMS message or bin treatment (panel A). "Avg. no. of bins turned in per week" reflects the volume of recyclables remitted in units of standard size bins. "Avg. market value of recyclables given per week" is estimated by valuing the quantities of different materials (for example, glass, paper) at the prices collectors receive for those items. "Avg. percentage of contamination per week" is the weight of nonrecyclable items included in the bag remitted to collectors divided by the total weight of the bag. Standard errors are shown in parentheses. Stars denote significance level of the difference: *, significant at the 10 percent confidence level; **, significant at the 5 percent confidence level; $* * *$, significant at the 1 percent confidence level. 
TA B LE 4b: Participation Intensity Study - Treatment Effect of Bins and SMS Messages on Recycling

\begin{tabular}{|c|c|c|c|c|c|}
\hline & $\begin{array}{l}\text { (1) } \\
\text { Percentage of visits } \\
\text { turned in bag }\end{array}$ & $\begin{array}{l}\text { (2) } \\
\text { Avg. no. of bins } \\
\text { turned in per week }\end{array}$ & $\begin{array}{l}\text { (3) } \\
\text { Avg. weight (in kg) } \\
\text { of recyclables turned in } \\
\text { per week }\end{array}$ & $\begin{array}{c}\text { (4) } \\
\text { Avg. market value } \\
\text { of recyclables given } \\
\text { per week }\end{array}$ & $\begin{array}{c}\text { (5) } \\
\text { Avg. percentage } \\
\text { of contamination } \\
\text { per week }\end{array}$ \\
\hline \multicolumn{6}{|l|}{ PANEL B: Subtreatments without interaction effects } \\
\hline Bin with sticker (1) & $\begin{array}{l}0.055^{* * *} \\
(0.015)\end{array}$ & $\begin{array}{l}0.128 * * * \\
(0.022)\end{array}$ & $\begin{array}{l}0.205^{* * *} \\
(0.042)\end{array}$ & $\begin{array}{l}0.125 * * * \\
(0.024)\end{array}$ & $\begin{array}{l}-0.012 \\
(0.009)\end{array}$ \\
\hline Bin without sticker (2) & $\begin{array}{l}0.035^{* * *} \\
(0.015)\end{array}$ & $\begin{array}{l}0.103 * * * \\
(0.022)\end{array}$ & $\begin{array}{l}0.17^{* * * *} \\
(0.041)\end{array}$ & $\begin{array}{l}0.091 * * * \\
(0.024)\end{array}$ & $\begin{array}{l}-0.006 \\
(0.009)\end{array}$ \\
\hline Personal SMS message & $\begin{array}{l}-0.009 \\
(0.017)\end{array}$ & $\begin{array}{l}-0.008 \\
(0.025)\end{array}$ & $\begin{array}{l}-0.046 \\
(0.047)\end{array}$ & $\begin{array}{l}-0.026 \\
(0.027)\end{array}$ & $\begin{array}{l}-0.008 \\
(0.010)\end{array}$ \\
\hline Generic SMS message & $\begin{array}{l}0.015 \\
(0.017)\end{array}$ & $\begin{array}{l}0.02 \\
(0.025)\end{array}$ & $\begin{array}{l}0 \\
(0.048)\end{array}$ & $\begin{array}{l}-0.013 \\
(0.027)\end{array}$ & $\begin{array}{l}0 \\
(0.010)\end{array}$ \\
\hline Has cell phone & $\begin{array}{l}0.022 \\
(0.014)\end{array}$ & $\begin{array}{l}0.046^{* *} \\
(0.020)\end{array}$ & $\begin{array}{l}0.104^{* * *} \\
(0.038)\end{array}$ & $\begin{array}{l}0.056^{* * *} \\
(0.022)\end{array}$ & $\begin{array}{l}0.01 \\
(0.008)\end{array}$ \\
\hline Percentage of visits turned in bag, baseline & $\begin{array}{c}0.374 * * * \\
(0.017)\end{array}$ & & & & \\
\hline Avg. no. of bins turned in per week, baseline & & $\begin{array}{c}0.374 * * * \\
(0.014)\end{array}$ & & & \\
\hline Avg. weight (in kg) of recyclables turned in per week, baseline & & & $\begin{array}{c}0.281^{* * *} \\
(0.011)\end{array}$ & & \\
\hline Avg. market value of recyclables given per week, baseline & & & & $\begin{array}{c}0.233^{* * *} \\
(0.010)\end{array}$ & \\
\hline Avg. percentage of contamination per week, baseline & & & & & $\begin{array}{c}0.292 * * * \\
(0.019)\end{array}$ \\
\hline Street fixed effects & Yes & Yes & Yes & Yes & Yes \\
\hline F-test p-value $(1)=(2)$ & 0.31 & 0.38 & 0.51 & 0.27 & 0.63 \\
\hline Observations & 1,781 & 1,781 & 1,781 & 1,781 & 1,588 \\
\hline R-squared & 0.34 & 0.44 & 0.38 & 0.35 & 0.34 \\
\hline Mean of dependent variable & 0.78 & 0.68 & 0.76 & 0.49 & 0.13 \\
\hline
\end{tabular}

Notes: The table shows household-level recycling variables in the participation intensity study regressed on indicators for specific SMS message or bin treatments (panel B). "Avg. no. of bins turned in per week" reflects the volume of recyclables remitted in units of standard size bins. "Avg. market value of recyclables given per week" is estimated by valuing the quantities of different materials (for example, glass, paper) at the prices collectors receive for those items. "Avg. percentage of contamination per week" is the weight of nonrecyclable items included in the bag remitted to collectors divided by the total weight of the bag. Standard errors are shown in parentheses. Stars denote significance level of the difference: *, significant at the 10 percent confidence level; $* *$, significant at the 5 percent confidence level; $* *$, significant at the 1 percent confidence level. 
TABLE 4c: Participation Intensity Study - Treatment Effect of Bins and SMS Messages on Recycling

\begin{tabular}{|c|c|c|c|c|c|}
\hline & $\begin{array}{l}\text { (1) } \\
\text { Percentage of visits } \\
\text { turned in bag }\end{array}$ & $\begin{array}{c}\text { (2) } \\
\text { Avg. no. of bins } \\
\text { turned in per week }\end{array}$ & $\begin{array}{l}\text { (3) } \\
\text { Avg. weight (in } \mathrm{kg} \text { ) of } \\
\text { recyclables turned in } \\
\text { per week }\end{array}$ & $\begin{array}{l}\text { (4) } \\
\text { Avg. market value of } \\
\text { recyclables given } \\
\text { per week }\end{array}$ & $\begin{array}{c}(5) \\
\text { Avg. percentage } \\
\text { of contamination } \\
\text { per week }\end{array}$ \\
\hline \multicolumn{6}{|l|}{ PANEL C: Fully saturated model } \\
\hline \multirow[t]{2}{*}{$\begin{array}{l}\text { Generic SMS message + Bin with } \\
\text { sticker (1) }\end{array}$} & 0.041 & $0.158 * * *$ & $0.285 *$ & $0.147 * *$ & -0.03 \\
\hline & $(0.041)$ & $(0.059)$ & $(0.112)$ & $(0.064)$ & $(0.024)$ \\
\hline Generic SMS message + Bin (2) & 0.025 & 0.056 & 0.154 & 0.092 & -0.029 \\
\hline \multirow{2}{*}{ Generic SMS message + No bin } & 0.019 & -0.019 & $\begin{array}{l}(0.106) \\
-0.035\end{array}$ & $\begin{array}{l}(0.060) \\
-0.033\end{array}$ & $\begin{array}{l}(0.023) \\
-0.01\end{array}$ \\
\hline & $(0.025)$ & $(0.036)$ & $(0.068)$ & $(0.039)$ & $(0.015)$ \\
\hline \multirow[t]{2}{*}{$\begin{array}{l}\text { Personal SMS message }+ \text { Bin with } \\
\text { sticker (3) }\end{array}$} & 0.036 & $0.124 * *$ & 0.099 & 0.053 & $-0.043^{*}$ \\
\hline & $(0.039)$ & $(0.057)$ & $(0.108)$ & $(0.062)$ & $(0.024)$ \\
\hline \multirow[t]{2}{*}{ Personal SMS message + Bin (4) } & $0.07^{*}$ & 0.059 & 0.115 & 0.041 & -0.032 \\
\hline & $(0.038)$ & $(0.055)$ & $(0.103)$ & $(0.059)$ & $(0.022)$ \\
\hline \multirow[t]{2}{*}{ Personal SMS message + No bin } & -0.027 & -0.054 & -0.051 & -0.018 & -0.017 \\
\hline & $(0.025)$ & $(0.036)$ & $(0.068)$ & $(0.039)$ & $(0.015)$ \\
\hline \multirow[t]{2}{*}{ No phone + Bin with sticker $(5)$} & $0.078 * * *$ & $0.127 * * *$ & $0.232 * * *$ & $0.149 * * *$ & -0.001 \\
\hline & $(0.020)$ & $(0.030)$ & $(0.056)$ & $(0.032)$ & $(0.012)$ \\
\hline \multirow[t]{2}{*}{ No phone + Bin $(6)$} & 0.03 & $0.1^{* * *}$ & $0.142 * *$ & $0.096 * * *$ & 0.004 \\
\hline & $(0.021)$ & $(0.030)$ & $(0.057)$ & $(0.032)$ & $(0.012)$ \\
\hline \multirow{2}{*}{$\begin{array}{l}\text { No SMS message }+ \text { Bin with sticker } \\
\text { (7) }\end{array}$} & 0.031 & 0.026 & 0.109 & 0.068 & $-0.049 * *$ \\
\hline & $(0.040)$ & $(0.058)$ & $(0.109)$ & $(0.062)$ & $(0.023)$ \\
\hline \multirow{2}{*}{ No SMS message + Bin $(8)$} & 0.045 & $0.114 \% *$ & $0.299 * \cdots$ & $0.114 *$ & -0.035 \\
\hline & $(0.039)$ & $(0.056)$ & $(0.107)$ & $(0.061)$ & $(0.023)$ \\
\hline \multirow{2}{*}{ No SMS message + No Bin } & -0.011 & $-0.061 *$ & -0.039 & -0.009 & -0.018 \\
\hline & $(0.025)$ & $(0.036)$ & $(0.067)$ & $(0.039)$ & $(0.015)$ \\
\hline
\end{tabular}


$0.373^{* * *}$

(0.017)

$$
\text { baseline }
$$

Avg. no. of bins turned in per week, baseline

Avg. weight (in $\mathrm{kg}$ ) of recyclables

turned in per week, baseline

Avg. market value of recyclables given per week, baseline

Avg. percentage of contamination per week, baseline

Street fixed effects

F-test p-value $(1)=(2)$

F-test p-value $(3)=(4)$

F-test p-value $(5)=(6)$

F-test p-value $(7)=(8)$

Observations

R-squared

Mean of dependent variable

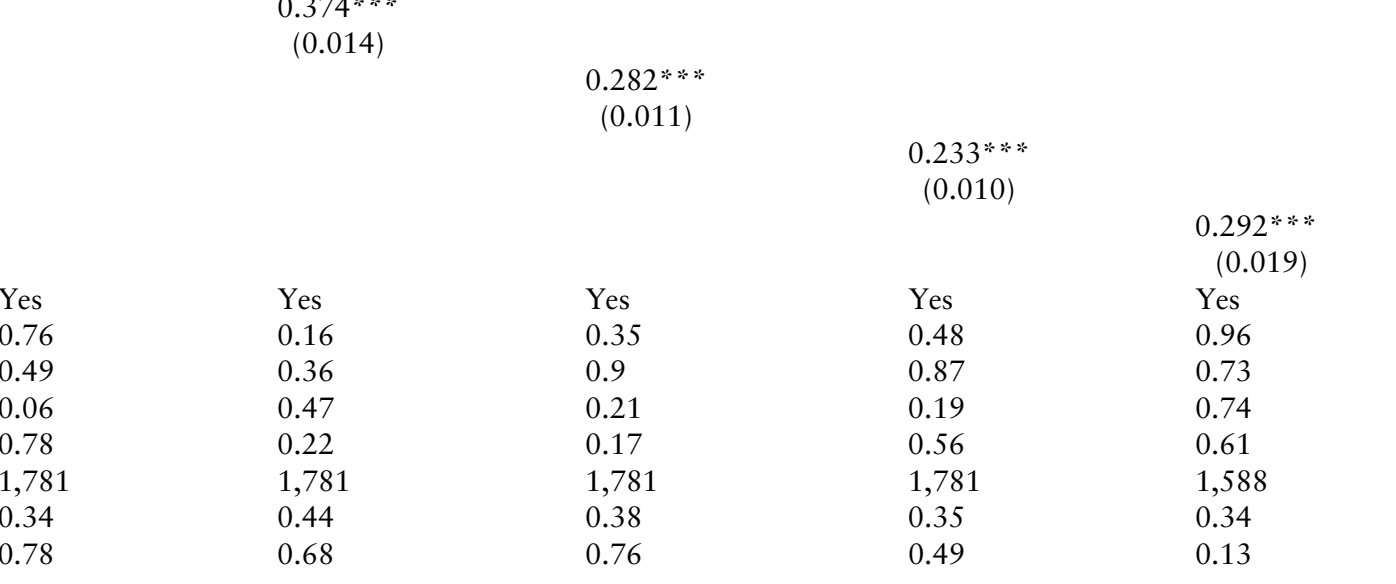

(3) recyclables turned in per week
Avg. weight (in kg) of

(4)

Avg. market value of recyclables given per week

$0.12^{* * *}$

(0.054)

0.068 * *

(0.031)

(0.028)

(5)

Avg. percentage of contamination per week

$0.027 * *$

(0.012)

$0.374 * *$

(0.014)

$0.282^{* *}$

$0.292 * *$

0.73

0.74

Notes: The table shows household-level recycling variables in the participation intensity study regressed on indicators for a fully saturated model with indicators for each unique combination of treatments ( panel C). "Avg. no. of bins turned in per week" reflects the volume of recyclables remitted in units of standard size bins. "Avg. market value of recyclables given per week" is estimated by valuing the quantities of different materials (for example, glass, paper) at the prices collectors receive for those items. "Avg. percentage of contamination per week" is the weight of nonrecyclable items included in the bag remitted to collectors divided by the total weight of the bag. Standard errors are shown in parentheses. Stars denote significance level of the difference: *, significant at the 10 percent confidence level; $* *$, significant at the 5 percent confidence level; $* * *$, significant at the 1 percent confidence level. 
Ta вLE 5: Participation Intensity Study - Treatment Effect of SMS Messages on Recycling

\begin{tabular}{|c|c|c|c|c|c|}
\hline & $\begin{array}{l}\text { (1) } \\
\text { Percentage of visits } \\
\text { turned in bag }\end{array}$ & $\begin{array}{l}\text { (2) } \\
\text { Avg. no. of bins } \\
\text { turned in per week }\end{array}$ & $\begin{array}{l}\text { Avg. weight (in } \mathrm{kg} \text { ) } \\
\text { of recyclables turned } \\
\text { in per week }\end{array}$ & $\begin{array}{c}\text { (4) } \\
\text { Avg. market value } \\
\text { of recyclables given } \\
\text { per week }\end{array}$ & $\begin{array}{c}(5) \\
\text { Avg. percentage } \\
\text { of contamination per } \\
\text { week }\end{array}$ \\
\hline \multicolumn{6}{|l|}{ Full sample } \\
\hline Personal SMS message & $\begin{array}{l}-0.009 \\
(0.017)\end{array}$ & $\begin{array}{l}-0.006 \\
(0.025)\end{array}$ & $\begin{array}{l}-0.043 \\
(0.048)\end{array}$ & $\begin{array}{l}-0.025 \\
(0.027)\end{array}$ & $\begin{array}{l}-0.008 \\
(0.01)\end{array}$ \\
\hline Generic SMS message & $\begin{array}{l}0.014 \\
(0.017)\end{array}$ & $\begin{array}{l}0.02 \\
(0.026)\end{array}$ & $\begin{array}{l}0 \\
(0.048)\end{array}$ & $\begin{array}{l}-0.013 \\
(0.027)\end{array}$ & $\begin{array}{l}0 \\
(0.01)\end{array}$ \\
\hline Has cell phone & $\begin{array}{l}0.021 \\
(0.014)\end{array}$ & $\begin{array}{l}0.043 * * \\
(0.021)\end{array}$ & $\begin{array}{l}0.098 * * \\
(0.039)\end{array}$ & $\begin{array}{l}0.053 * * \\
(0.022)\end{array}$ & $\begin{array}{l}0.01 \\
(0.008)\end{array}$ \\
\hline $\begin{array}{l}\text { Percentage of visits turned in bag, } \\
\text { baseline }\end{array}$ & $\begin{array}{l}0.376 * * * \\
(0.017)\end{array}$ & & & & \\
\hline $\begin{array}{l}\text { Avg. no. of bins turned in per week, } \\
\text { baseline }\end{array}$ & & $\begin{array}{l}0.375 * * * \\
(0.025)\end{array}$ & & & \\
\hline $\begin{array}{l}\text { Avg. weight (in } \mathrm{kg} \text { ) of recyclables } \\
\text { turned in per week, baseline }\end{array}$ & & & $\begin{array}{l}0.28 * * * \\
(0.011)\end{array}$ & & \\
\hline $\begin{array}{l}\text { Avg. market value of recyclables given } \\
\text { per week, baseline }\end{array}$ & & & & $\begin{array}{c}0.231 * * * \\
(0.010)\end{array}$ & \\
\hline $\begin{array}{l}\text { Avg. percentage of contamination per } \\
\text { week, baseline }\end{array}$ & & & & & $\begin{array}{l}0.293 * * * \\
(0.019)\end{array}$ \\
\hline Street fixed effects & Yes & Yes & Yes & Yes & Yes \\
\hline P-value & 0.23 & 0.37 & 0.42 & 0.71 & 0.51 \\
\hline Observations & 1,781 & 1,781 & 1,781 & 1,781 & 1,588 \\
\hline R-squared & 0.33 & 0.42 & 0.36 & 0.34 & 0.34 \\
\hline Mean of dependent variable & 0.78 & 0.68 & 0.76 & 0.49 & 0.13 \\
\hline
\end{tabular}

Notes: The table shows household-level recycling variables in participation intensity study regressed on the different specifications of the text message treatment. The results for an f-test of an equal effect for each treatment are also shown. Samples are restricted as specified. Standard errors are shown in parentheses. Stars denote significance level of the difference: *, significant at the 10 percent confidence level; $* *$, significant at the 5 percent confidence level; $* * *$, significant at the 1 percent confidence level. 
Panels $\mathrm{A}, \mathrm{B}$, and $\mathrm{C}$ of table 4 show the estimates from equations 3-5, which indicate highly significant effects of bin provision on recycling behavior. The magnitudes are consistent with those estimated by examining the effect of bins in isolation. The final panel presents results from a full model with indicator variables for every possible combination of treatments (no phone and no bin is the omitted category). We generally find statistically significant and positive effects of treatment on recycling behavior when the treatment includes the provision of a bin.

\section{Discussion of Participation Intensity Study}

The participation intensity results suggest that forgetfulness is not a serious constraint to recycling among households that have already self-selected into the recycling program. Rather, it appears that the inconvenience of storing recyclables for the collectors represents a substantive barrier. Indeed, households reported that they did not want to keep recyclable refuse around the house because it occupies space and attracts insects. This finding is consistent with the case made in Carlson (2001) that reducing the costs incurred by individuals when engaging in proenvironmental behavior is the most effective way to change behavior.

Doing so, however, requires that some resources must be dedicated to reducing those costs. In this context, this is the cost of providing the bin to households. Given that recyclables represent an income stream to the collectors who gather and resell them, it is possible that investing in bin provision represents a profitable prospect, even abstracting from the nonmonetary benefits of additional recycling. To address this issue, we estimate the benefits of investing in bins compared with the provision of one recycling bag per week to each participating family, as is currently done by PRISMA.

Our point estimates suggest that an investment of 14 soles (the cost of a bin without a sticker) leads to an increase of 0.09 soles worth of recyclables turned in by each household each week. Additionally, households that receive a bin increase the percentage of weeks in which they turn in recyclables by 3.7 percentage points. Among the group that received no intervention, households turned in recyclables 76 percent of the time, with an average value of 0.418 soles per week. Therefore, the value of the increased participation intensity induced by the bin is $(52$ weeks $) \times(76 \%) \times(0.09$ soles $)+(52$ weeks $) \times(3.7 \%) \times(0.09$ soles $)+$ 4.18 soles, or 4.53 soles. Adding the benefit of not having to buy the recycling bags $(0.075$ soles per family per participating week) yields an additional benefit of $(52$ weeks $) \times(76 \%) \times(0.075$ soles $)=2.96$ soles, for a total benefit of 7.494 soles per household per year.

In contrast, an investment of 14.87 soles (the cost of a bin with an informational sticker) increases weekly participation rates by 6 percent and the average value of recyclables by 0.107 soles per week. A similar calculation yields an additional benefit of 8.827 soles per household per year. As shown in the table below, if PRISMA is able to retain households in the program for two years, 
investment in bins would increase the quantity of items recycled through the program and the income of collectors beyond the cost of the bins.

\begin{tabular}{lccc}
\hline Type of bin & Price & $\begin{array}{c}\text { Annual benefit/family } \\
\text { for collector }\end{array}$ & Time to break even \\
\hline Bin without sticker & 5.00 USD $^{17}$ & 2.68 USD & 21.4 months \\
Bin with sticker & $(14.00$ soles $)$ & $(7.49$ soles $)$ & 20.2 months \\
& 5.31 USD & 3.15 USD & \\
\hline
\end{tabular}

\section{CONCLUSIONS}

As part of a randomized evaluation of a recycling program in Peru, we tested a number of popular messaging approaches to environmental behavioral change, including information, reminders, social norms, appeals to the threat of social sanction, and authority endorsement. We found that none of the informational messages, many of which were similar to messages that have been found to be successful in developed country contexts, were effective in increasing participation in this program. This is a fairly precise null result; we are able to rule out effects of relatively small magnitudes. We find, however, that the provision of bins that make recycling more convenient and cleaner increases participation levels substantially and would be a cost-effective expansion strategy for PRISMA's program.

These results suggest that the lessons drawn from campaigns promoting prosocial behaviors may not generalize across contexts and countries, indicating that there are substantial gains to continued theory (to model what specific contextual factors influence treatment effects) as well as experimentation and evaluation to test more robust theories that incorporate more contextual factors. Furthermore, we find that the single treatment that changed the relative costs and benefits of the recycling choice (reducing the cost of recycling by providing recycling bins) changed behavior, whereas the treatments that merely changed messaging had no effect.

\section{REFERENCES}

Alcott, H. 2009. "Social Norms and Energy Conservation." Center for Energy and Environmental Research, Massachusetts Institute of Technology, Cambridge, MA.

Alpizar, F., F. Carlsson, and O. Johansson-Stenman. 2008. “Anonymity, Reciprocity, and Conformity: Evidence from Voluntary Contributions to a National Park in Costa Rica." Journal of Public Economics 92 (5-6): 1047-60.

Bertrand, M., D. Karlan, S. Mullainathan, E. Shafir, and J. Zinman. 2009. "What's Advertising Content Worth? Evidence form a Consumer Credit Marketing Field Experiment." Quarterly Journal of Economics 125 (1): 263-305.

17. Currency conversion is based on the average 2010 exchange rate. 
Bryce, W. J., R. Day, and T. J. Olney. 1997. "Commitment Approach to Motivating Community Recycling: New Zealand Curbside Trial.” The Journal of Consumer Affairs 31 (1): 27-52.

Burn, S. M., and S. Oskamp. 1986. "Increasing Community Recycling with Persuasive Communication and Public Commitment." Journal of Applied Social Psychology 16: 29-41.

Burn, S. M. 1991. "Social Psychology and the Stimulation of Recycling Behaviors: The Block Leader Approach.” Journal of Applied Social Psychology 21 (8): 611-29.

Carlson, A. E. 2001. “Recycling Norms.” California Law Review 89 (5): 1231-300.

Chauvin, L. 2009. "Peru's Scavengers Turn Professional.” Time Magazine, February 10. http://www. time.com/time/world/article/0,8599,1878475,00.html.

Choi, J. J., E. Haisley, J. Kurkoski, and C. Massey. 2012. “Small Cues Change Savings Choices.” NBER Working Paper 17843. National Bureau of Economic Research, Cambridge, MA.

Chu, P.-Y., and J.-F. Chiu. 2003. "Factors Influencing Household Waste Recycling Behavior: Test of an Integrated Model." Journal of Applied Social Psychology 33 (3): 604-26.

Cialdini, R. B., and N. J. Goldstein. 2004. "Social Influence: Compliance and Conformity.” Annual Review of Psychology 55: 591-621.

Elster, J. 1989. “Social Norms and Economic Theory.” Journal of Economic Perspectives 3 (4): 99-117.

Frey, B. S., and S. Meier. 2004. "Social Comparisons and Pro-social Behavior: Testing 'Conditional Cooperation' in a Field Experiment.” American Economic Review 94 (5): 1717-22.

Gerber, A. S., D. P. Green, and C. W. Larimer. 2008. "Social Pressure and Voter Turnout: Evidence from a Large-Scale Field Experiment.” American Political Science Review 102 (1): 33-48.

Goldstein, N. J., R. B. Cialdini, and V. Griskevicius. 2008. “A Room with a Viewpoint: Using Social Norms to Motivate Environmental Conservation in Hotels." Journal of Consumer Research 35 (3): 472-82.

Karlan, D., M. McConnell, S. Mullainathan, and J. Zinman. 2011. "Getting to the Top of Mind: How Reminders Increase Saving.” NBER Working Paper 16205. National Bureau of Economic Research, Cambridge, MA.

Lerner, J. S., and P. E. Tetlock. 1999. “Accounting for the Effects of Accountability.” Psychological Bulletin 125: 255-75.

Lord, K. R. 1994. "Motivating Recycling Behavior: A Quasiexperimental Investigation of Message and Source Strategies." Psychology \& Marketing 11 (4): 341-58.

Milgram, S. 1974. Obedience to Authority. New York: Harper \& Row.

Pew Global Attitudes Project. 2007. "Spring 2007 Survey of 47 Publics: Final 2007 Trends Topline.” Accessed September 20, 2011. http://pewglobal.org/files/pdf/258topline.pdf.

Schultz, P. W. 1999. "Changing Behavior with Normative Feedback Interventions: A Field Experiment on Curbside Recycling.” Basic and Applied Social Psychology 21 (1): 25-36.

Stango, V., and J. Zinman. 2011. "Limited and Varying Consumer Attention: Evidence from Shocks to the Salience of Bank Overdraft Fees." NBER Working Paper No. 17028. National Bureau of Economic Research, Cambridge, MA.

Thaler, R., and C. R. Sunstein. 2008. Nudge: Improving Decisions About Health, Wealth and Happiness. New Haven, CT: Yale University Press.

World Values Survey. 2005. “World Values Survey 2005 Official Data File v.20090901.” Accessed April 22, 2013. http://www.wvsevsdb.com/wvs/WVSData.jsp?Idioma=I.

. 2009. "World Values Survey 1981-2008 Official Aggregate v. 20090901.” Accessed September 20, 2011. http://www.wvsevsdb.com/wvs/WVSData.jsp?Idioma=I.

Zwane, A. P., J. Zinman, E. V. Dusen, W. Pariente, C. Null, E. Miguelb, M. Kremerb, D. S. Karlanb, R. Hornbeckh, X. Ginéb, E. Duflo, F. Devotob, B. Creponc, and B. Abhijit. 2010. "Being Surveyed Can Change Later Behavior and Related Parameter Estimates." Proceedings of the National Academy of Sciences 108 (5): 1821-26. 